\title{
Ammonia in the summertime Arctic marine boundary layer: sources, sinks, and implications
}

\section{G. R. Wentworth et al.}

Correspondence to: Jennifer G. Murphy (jmurphy@chem.utoronto.ca)

The copyright of individual parts of the supplement might differ from the CC-BY 3.0 licence. 
2 Table $\mathrm{S} 1$. Surface ocean parameters relevant for determining surface-air $\mathrm{NH}_{3}$ exchange

\begin{tabular}{|c|c|c|c|c|}
\hline Date and Time (UTC) & Lat $\left({ }^{\circ} \mathrm{N}\right)$ & Lon $\left({ }^{\circ} \mathrm{W}\right)$ & {$\left[\mathrm{NH}_{\mathrm{x}}\right](\mathrm{nM})$} & $\operatorname{SST}\left({ }^{\circ} \mathrm{C}\right)$ \\
\hline 2014-07-15 9:12 & 69.3672 & 64.8667 & $<20$ & 2.68 \\
\hline 2014-07-17 21:42 & 74.1566 & 80.4861 & $<20$ & 6.18 \\
\hline 2014-07-19 13:15 & 74.1084 & 83.4386 & $<20$ & 3.58 \\
\hline 2014-07-19 19:21 & 74.0991 & 83.4067 & $<20$ & 3.38 \\
\hline 2014-07-20 17:08 & 74.2391 & 91.5339 & $<20$ & -0.54 \\
\hline 2014-07-20 19:18 & 74.2339 & 91.4947 & $<20$ & -0.59 \\
\hline 2014-07-22 9:32 & 74.3199 & 94.9029 & $<20$ & -0.15 \\
\hline 2014-07-27 15:37 & 73.2906 & 63.6075 & 22 & 2.99 \\
\hline 2014-07-28 17:43 & 73.2611 & 57.8854 & 20 & 5.73 \\
\hline 2014-07-29 22:26 & 75.4001 & 61.6649 & $<20$ & 5.06 \\
\hline 2014-07-30 18:44 & 76.3347 & 71.2126 & 58 & 3.06 \\
\hline 2014-07-30 21:42 & 76.3212 & 71.1668 & 49 & 3.18 \\
\hline 2014-07-25 17:00 & 74.4525 & 89.2145 & 380 & 0.82 \\
\hline 2014-07-25 19:00 & 74.4114 & 87.6705 & 104 & 3.21 \\
\hline 2014-07-25 21:30 & 74.4583 & 85.6265 & $<20$ & 3.16 \\
\hline 2014-07-25 23:00 & 74.449 & 84.4133 & 136 & 4.4 \\
\hline 2014-07-16 10:30 & 71.5087 & 70.2804 & $<20$ & 5.34 \\
\hline 2014-07-31 15:30 & 76.3056 & 73.2270 & $<20$ & 4.5 \\
\hline 2014-08-01 1:30 & 76.2675 & 74.5992 & $<20$ & 4.32 \\
\hline 2014-08-01 10:30 & 76.3137 & 75.7749 & $<20$ & 4.69 \\
\hline 2014-08-01 21:40 & 76.3708 & 77.4110 & $<20$ & 2.67 \\
\hline 2014-08-02 17:40 & 78.461 & 73.8764 & 294 & 1.84 \\
\hline 2014-08-02 18:20 & 78.5946 & 73.5861 & 310 & 1.11 \\
\hline 2014-08-02 19:30 & 78.8293 & 73.0194 & $<20$ & 0.84 \\
\hline 2014-08-02 20:20 & 78.9863 & 72.5310 & 44 & 0.87 \\
\hline 2014-08-02 20:40 & 79.0496 & 72.3455 & 42 & 0.96 \\
\hline 2014-08-02 21:30 & 79.2011 & 71.7628 & 275 & 0.94 \\
\hline 2014-08-02 21:40 & 79.2245 & 71.6052 & 176 & 0.96 \\
\hline 2014-08-02 22:30 & 79.3809 & 71.1979 & $<20$ & 2.22 \\
\hline 2014-08-02 22:40 & 79.401 & 71.0861 & 58 & 2.13 \\
\hline 2014-08-03 16:50 & 81.3601 & 63.9560 & 54 & -0.59 \\
\hline 2014-08-04 6:30 & 80.7955 & 67.3011 & $<20$ & -0.1 \\
\hline 2014-08-04 18:10 & 79.9931 & 69.7773 & $<20$ & 0.46 \\
\hline 2014-08-05 8:30 & 79.3461 & 71.8578 & $<20$ & 2.68 \\
\hline 2014-08-06 1:50 & 79.0015 & 73.2046 & $<20$ & 1.99 \\
\hline 2014-08-06 15:50 & 77.3259 & 75.7041 & 20 & 3.63 \\
\hline 2014-08-07 12:40 & 74.7331 & 78.3273 & $<20$ & 4.5 \\
\hline 2014-08-07 12:50 & 74.7019 & 78.3784 & 26 & 4.65 \\
\hline
\end{tabular}


1 Table S2. Melt pond parameters relevant for determining surface-air $\mathrm{NH}_{3}$ exchange

\begin{tabular}{|c|c|c|c|c|c|c|}
\hline Date and Time $(\mathrm{UTC})$ & Lat $\left({ }^{\circ} \mathrm{N}\right)$ & Lon $\left({ }^{\circ} \mathrm{W}\right)$ & {$\left[\mathrm{NH}_{\mathrm{x}}\right](\mathrm{nM})$} & Temp $\left({ }^{\circ} \mathrm{C}\right)$ & $\mathrm{pH}$ & Salinity \\
\hline 2014-07-18 18:00 & 73.5191 & 80.9863 & 706 & 1.86 & 7.2 & 5.2 \\
\hline 2014-07-18 18:00 & 73.5191 & 80.9863 & 896 & 1.82 & 7.1 & 4.1 \\
\hline 2014-07-21 2:00 & 74.2795 & 91.6322 & 779 & 0.42 & 6.7 & 1.3 \\
\hline $2014-07-212: 00$ & 74.2795 & 91.6322 & 1042 & 0.31 & 6.7 & 0.4 \\
\hline $2014-07-212: 00$ & 74.2795 & 91.6322 & 739 & 0.23 & 6.7 & 0.2 \\
\hline 2014-07-21 18:00 & 74.2387 & 92.2041 & 1262 & 0.21 & 6.9 & 1.1 \\
\hline $2014-07-2118: 00$ & 74.2387 & 92.2041 & 642 & 0.21 & 6.9 & 0.9 \\
\hline $2014-07-2317: 30$ & 74.6033 & 94.9108 & $<20$ & 0.80 & 7.0 & 8.1 \\
\hline $2014-07-2317: 30$ & 74.6033 & 94.9108 & $<20$ & 0.23 & 7.0 & 8.5 \\
\hline
\end{tabular}

2

3 